\title{
MEASUREMENT OF DOWNHOLE STEAM QUALITY \\ AND \\ TOTAL ENERGY BY OPTICAL METHODS
}

\author{
Semi-Annual Report
}

Reporting Period Start Date: October, 1997

Reporting Period End Date: $\quad$ March, 1998

Dr. A.B. Donaldson and Dr. Graham R. Allan

April, 1998

DOE AWARD NUMBER DE-FG26-97FT97279

Departments of Engineering and Physics

New Mexico Highlands University, National Avenue

Las Vegas, NM 87701. 


\section{$\underline{\text { Disclaimer }}$}

This report was prepared as an account of work sponsored by an agency of the United States Government. Neither the United States Government nor any agency thereof, nor any of their employees, makes any warranty, express or implied, or assumes any legal liability or responsibility for the accuracy, completeness, or usefulness of any information, apparatus, product, or process disclosed, or represents that its use would not infringe privately owned rights. Reference herein to any specific commercial product, process, or service by trade name, trademark, manufacturer, or otherwise does not necessarily constitute or imply its endorsement, recommendation, or favoring by the United States Government or any agency thereof. The views and opinions of authors expressed herein do not necessarily state or reflect those of the United States Government or any agency thereof. 


\begin{abstract}
$\underline{\text { Abstract }}$
Initial steps have been taken to measure the mass of water in vapor and liquid phases downhole in a steam injection heavy oil recovery system. A suitable portion of the electromagnetic spectrum has been identified over which the presence of liquid water and vapor can be separated. This is in the near infrared and extends from $\sim 900 \mathrm{~nm}$ to $1.8 \mu \mathrm{m}$ region. A high pressure and high temperature cell has been constructed and tested for stagnant transmissions. Pitting of the optical ports due to the presence of high-pressure (8.5 MPA) and high temperature (300C) water has lead to a redesign of the optical ports, these modifications will be incorporated in the next quarter. The actual determination of the mass of water, either in liquid or vapor, has not been reliably determined, due in part to the pitting problems being addressed in the modification. However, qualitative data has been recorded clearly showing an increase in absorption with increasing number of absorbing molecules, i.e. mass of water.
\end{abstract}




\section{TABLE OF CONTENTS}

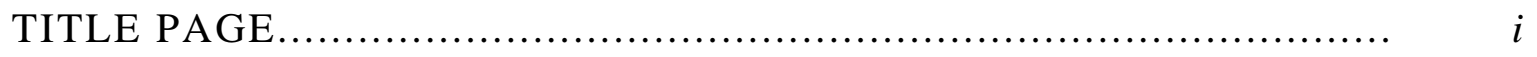

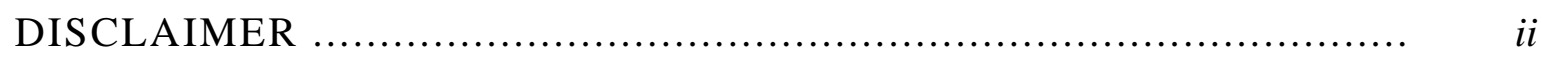

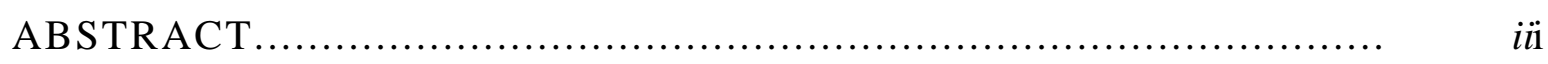

TABLE OF CONTENTS ............................................... iv

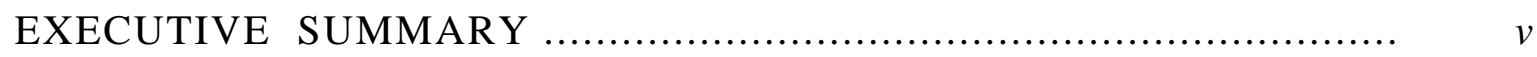

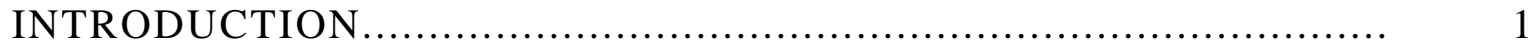

SCIENTIFIC DISCUSSION ........................................... 2

RESULTS AND DISCUSSION ......................................... 6

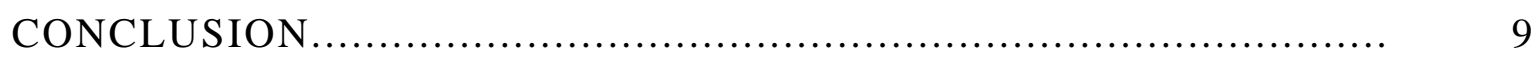




\title{
MEASUREMENT OF DOWNHOLE STEAM QUALITY AND TOTAL ENERGY BY OPTICAL METHODS
}

\author{
Semi-Annual Report
}

\section{Executive Summary}

In this project, an optical method is to be developed to measure the quality and total energy of a high pressure flow of steam. The configuration and technique for the device will be compatible with downhole deployment in heavy oil recovery steam injection operations. In conjunction with the development of a sensor, a data acquisition/data storage system will be adapted.

The system will be demonstrated under three successively more challenging applications. First, a laboratory generated and precisely known flow of water in air will be created to demonstrate the function of the device for the expected two-phase flow regimes. Next, the device and data acquisition system will be "fieldtested" in the distribution system for the University steam plant. Multiple devices will allow calculation of heat loss in the system and support a commercial study which will audit the costs for that operation. Finally, the device will be demonstrated in an oilfield situation; first in surface distribution piping, and second, in a downhole application. The downhole application will require, as a prerequisite, the development of appropriate hardware for the transmission of downhole data to the surface, which is compatible with the traditional installation and operating practices.

Because the concept for this design is relatively simple, the proof-of-principle demonstration can be accomplished in the first year of the development, with the remainder of the contract term being devoted to solving problems related to adaption of the technology to the various applications where a major impact can be made. These adaption efforts will be made in cooperation with end users of the technology, including the University heating plant system and an oil company currently utilizing thermal EOR.

A suitable spectrum has been identified over which the presence of liquid water and vapor can be identified. This is in the near infrared and extends from $\sim 900 \mathrm{~nm}$ to $1.8 \mu \mathrm{m}$ region. A high pressure and high temperature cell has been constructed and tested for stagnant transmission. Minor teething problems have led to an improved design which will resist corrosion of the optical ports. These modifications will be incorporated in the next quarter.

The actual determination of the mass of water, either in liquid or vapor, has not been reliably determined, due in part, to the teething problems addressed in the modifications. However, qualitative data has been recorded clearly showing an increase in absorption with increasing number of absorbing molecules, i.e. mass of water. Over the next quarter, construction of a two phase flowing cell will be undertaken. The velocity measurements apparatus will be further researched. 


\section{Problem Statement}

\section{INTRODUCTION}

Heavy oil represents a substantial fraction of world liquid hydrocarbon reserves. Conventional production practices leave a large percentage of this oil, partly because high viscosity at reservoir conditions inhibits flow to production wells. Ultimate recovery by conventional production frequently is below $10 \%$ and in a number of fields it is zero. Steam injection is the most widely utilized method for stimulating the production of heavy oil; currently accounting for around $80 \%$ [1]. However, the steam quality delivered to the reserve is largely an unknown quantity. It is the purpose of this research to develop a downhole instrument to measure the steam quality in realtime and hence the efficiency of steam delivery systems.

On a worldwide basis, heavy oil is found at depths varying from surface occurrence to as deep as 12,000 feet [2] and in the United States, more than three-fourths of heavy oil fields with more than 20 million barrels in place, occur at depths greater than 1500 feet [3]. In steam injection, steam is generated on the surface in a conventional high pressure boiler, utilizing a field-available fuel, and is conducted to the formation through injection tubing which is installed inside the well casing. However, as the depth to the formation becomes greater, surface area heat losses also become greater. In order to deal with this situation, various methods are employed to reduce the heat loss. The most common is simple insulated tubing which has been manufactured by enclosing a high temperature insulator material between a smaller diameter and a larger diameter tubing. Because of the difficulty in producing a design which will simultaneously make-up on both an inner and outer thread, one of the tubings is usually truncated just ahead of the thread on the other tubing, thus leaving an uninsulated collar. Thermal packers have been utilized in an attempt to isolate the annulus between the outer tubing and the casing from the formation, so that it will boil dry because of heat transfer from the bare collars during steaming. Due to the lack of inexpensive instrument packages designed to measure the energy in the steam when it reaches the oil formation, heat losses have had to be estimated based on postulated models for the overall heat transfer coefficient [4]. This requires some assumptions related to the state of fluid in the annulus and the energy transport processes occurring therein. The assumption has generally been that the annulus is occupied by a conducting/convecting gas. However, research has found that the annulus does not boil dry and in most situations; some water is present due to packer leaks, casing leaks, injecting tubing leaks, or the fact that no attempt was made to purge the annulus of fluids $[5,6]$. Therefore, depending on the injection rate, the injection pressure and total depth to the formation, substantial heat losses can occur in spite of expensive preventative measures. The magnitude of the heat losses are realized through poor performance results for the oil recovery stimulation.

A variety of alternatives have been considered and in some cases, installed in an attempt to improve the performance of the insulation systems. Among these ideas are low conductivity fluids in the well annulus, continuous evacuation methods for annulus water, casing collar inserts, a double walled insulated tubing which can be made-up on both inner and outer threads, etc. The 
latter design is accomplished by use of a bellows arrangement on one tubing to allow relative elongation for simultaneous thread make-up. The degree of improvement for these designs is usually obtained by calculation based on only one-dimensional heat conduction, by demonstration in a short section laboratory test rig with a dry annulus, or in a steam injection well which has been instrumented for a short distance below the surface (an area which Willhite [6] has shown to be generally free of the major energy dissipating mechanism of wellbore refluxing). A reliable, field tested device which measures the total energy content of the injected steam, however, is the ultimate tool for comparison of efficacy of these various designs.

A number of patents have been issued for different methods or differing embodiments for measuring steam quality in surface distribution lines and at the sand-face downhole. The favorite technique is based on the pressure drop measurements as the steam passes through an area constriction, see example [7,8]. This requires the accurate measurement of pressures which is not easy at downhole conditions. Other methods use acoustic velocity measurement (which does not accommodate the possible different flow regimes) or neutron absorption $[9,10]$. Because of the difficulty of making the measurement by these previous methods, none have seen significant field deployment, at least for downhole applications.

A consideration in the design of a steam quality tool is the degree of flow disturbance which can be tolerated, particularly in a manifolded distribution system. In other words, if the tool causes a permanent pressure loss, then the balance of the distribution system will be affected and influence the results. Consequently, one criteria for the design should be a minimum of flow disturbance. Similarly, before any design can receive widespread acceptance, it must be demonstrated downhole during an actual steam operation. This will provide the "testing under fire" in the very difficult environment which must be accommodated for downhole operation.

An option for deployment of the device which would greatly expand the utility for a downhole steam quality measurement device is a wireline/lubricator installable version. If this embodiment could be demonstrated, it would greatly facilitate and expand utilization because no installation would be necessary when the injection tubing is run-in to the well. This possibility is so attractive that some effort must be devoted to a study. The success is probably more dependent on finding a shop which will custom draw and weld continuous tubing, than it is dependent on the basic principles of operation.

\section{Scientific Discussion}

Steam quality is defined as the ratio of mass in the vapor phase divided by the total mass including vapor and liquid. The composite density of a two phase mixture of liquid and vapor can be expressed in terms of the density of the saturated liquid, the density of the saturated vapor and the quality by the expression

$$
\rho=\rho_{\mathrm{f}}+x \rho_{\mathrm{fg}}
$$

where the subscript-f identifies a saturated liquid property subscript-fg identifies the change in a 
property between the saturated liquid and saturated vapor values and $x$ is the quality. Since for two phases of a single component system in equilibrium, the system temperature and pressure are not independent, then either can be specified in order to determine the density of saturated liquid and vapor. Therefore, if the composite density of the system can be determined, along with either the pressure and temperature, then quality can be determined. This will then fix the specific enthalpy of the system. Furthermore, from this measured composite density, a known cross-sectional area and a measured average velocity, then the mass flow rate can be calculated from the equation

$$
\dot{\mathrm{m}}=\rho \mathrm{A} \overline{\mathrm{V}}
$$

Now with the mass flow rate determined, the total energy can be computed. Thus, if a device can be developed which will measure both the average density and the average velocity of a twophase flow, then quality and total energy can be calculated.

In determining the average density, $\rho$, of water molecules in a steam pipe one can take advantage of light absorption in water. Each molecule of $\mathrm{H}_{2} \mathrm{O}$ absorbs a fixed and known amount of light, the more molecules the greater the absorption. However in a simple transmission system any loss of transmitted light due to scattering from the droplets, reflection and coupling losses can lead to a large error in the measured average density. To surmount these problems a differential transmission technique can be employed. In this method the transmission of two frequencies of light, relatively close to each other in frequency are measured with respect to each other. On propagation through the system the main difference between the two signals is that one frequency is chosen to have a higher absorption and hence lower transmission through the sampled volume. The advantage of this technique is that it self-calibrates for losses in the system and uniquely determine the average number density of water molecules in the sampled volume. From this number the average density can be computed. An additional advantage of this technique is the scattered light can also be used to determine the velocity of the flow through the sampled volume. To determine the velocity of flow one can use Laser Doppler velocimetry. A technique (identical to that in use by the Police to measure velocities of vehicles) where the back scattered light is frequency shifted proportional to the velocity of the object. The back scattered light can then be collected and heterodyned with the source to determine the velocity of the flow.

To designing a system in which Laser Doppler Velocimetry and differential optical spectroscopy can be performed in parallel and insitu require that the following conditions be met: $i$. The choice of frequencies have differing absorbance in $\mathrm{H}_{2} \mathrm{O}$, ii. chosen frequencies match available sources and iii. easily transmitted over long distance in an optical fiber. Conveniently in the 800-1600nm band of the infrared all three conditions can be met. Laser diode sources are available commercially and can be tuned to the $\mathrm{H}_{2} \mathrm{O}$ absorption band at $938 \mathrm{~nm}$, or to a high-transmission window at say $900 \mathrm{~nm}$. Both these frequencies are easily transmitted down fibers using existing technology with $\sim 3 \mathrm{~dB} / \mathrm{Km}$ attenuation. With such sources the inherent system losses such as, insertion loss, reflection loss and backscatter are similar for both frequencies and can be easily removed from the measurements. The most significant difference will be due to the greater 
absorption of one frequency with respect to the other on transmission through the steam. A ratiometric measurement then self corrects for losses and determines absorption due to water molecules.

Figure 1 shows a sketch of the system and greatly exaggerates the size of the optical components for clarity. The whole system consists of 2 sources, 4 detectors and transmission fiber to the sensing head. The sensing head is passive with all electronics mountable on the surface. To correct, in real time, for possible fluctuations in the output of the laser diodes the output power is monitored using detectors M1 and M2 and ratioed with their respective transmitted signals recorded by D1 and D2. The light, as it propagate through the steam pipe is selectively attenuated due to the presence of water. In the schematic the lower signal is absorbed more on transmission through the steam than the upper beam.

\section{Schematic of Downhole Transmission and Detection $\mathrm{SJ}$}

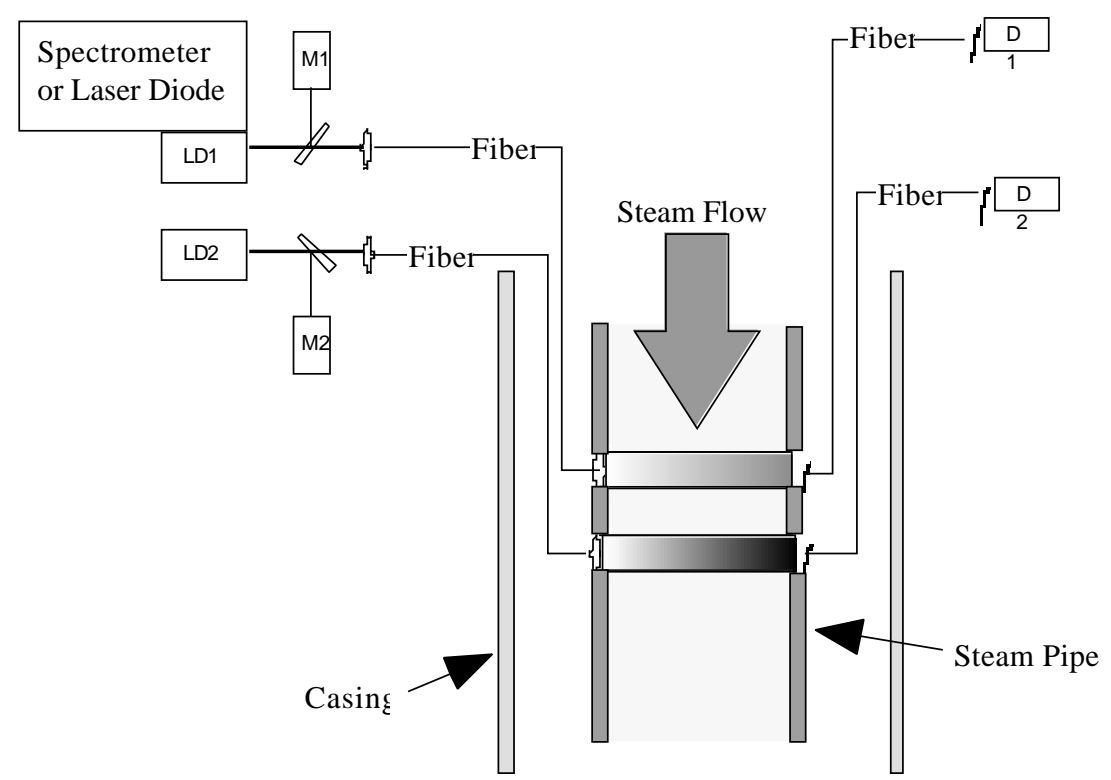

Figure 1. Schematic of the proposed differential measurement. M1 and M2 are detectors which monitor the output of the laser diodes LD1 \& LD2 The laser diodes output is then fiber coupled to the steam pipe. The transmitted light is collected and focused into the return fiber for measurement at the surface using detectors D1 \& D2.

The transmission of light through a column of absorbing medium is given by Beer's law where

$$
\mathrm{I}_{\mathrm{T}}=\mathrm{I}_{0} \mathrm{e}^{-\alpha l}
$$

where $\mathrm{I}_{\mathrm{T}}$ is the transmitted intensity, $\mathrm{I}_{0}$ is the incident intensity, $\alpha$ is the frequency dependent absorption coefficient $\left(\mathrm{cm}^{-1}\right)$ and $l$ is the sample length $(\mathrm{cm})$. The absorption coefficient $\alpha$ is determined from the number of absorbing sites and the absorption cross-section of water to light 
at the frequency of the source. $\alpha=\sigma \mathrm{N}$, where $\sigma$, is the absorption cross-section, $\left(\mathrm{cm}^{2}\right)$ and $\mathrm{N}$ is the number of water molecules/ unit volume, $\left(\mathrm{cm}^{-3}\right)$. To determine $\mathrm{N}$ from this measurement and hence $\rho$, the average density, requires ratioing the two transmitted signals.

$$
\mathrm{T}=\frac{\mathrm{T}_{2}}{\mathrm{~T}_{1}}=\frac{\mathrm{e}^{-\mathrm{N} \sigma_{2} l}}{\mathrm{e}^{-\mathrm{N} \sigma_{1} l}}
$$

In terms of the number density $\mathrm{N}:-\mathrm{N}=\frac{1}{l\left(\sigma_{1}-\sigma_{2}\right)} \ln \left(\frac{\mathrm{T}_{2}}{\mathrm{~T}_{1}}\right) \mathrm{cm}^{-3}$

The absorption coefficients and hence $\sigma$ are determined by the choice of wavelengths, $l$ is measured path length through the sample and $T_{1}$ and $T_{2}$ are the measured transmissions of the source 1 and 2; Signal $\left(\mathrm{D}_{2} / \mathrm{M}_{2}\right)$ and Signal $\left(\mathrm{D}_{1} / \mathrm{M}_{1}\right)$. The density of water vapor/liquid in the sampled volume is calculated from $\rho=\mathrm{N}$ x (Atomic Weight of $\mathrm{H}_{2} \mathrm{O}$ )/ $\mathrm{N}_{\mathrm{A}} \cdot \mathrm{gm} / \mathrm{cm}^{3}$ ). Note that both frequencies can be absorbed by the water, it is the difference in absorption that gives rise to the desired signal. The greater the difference the bigger the signal.

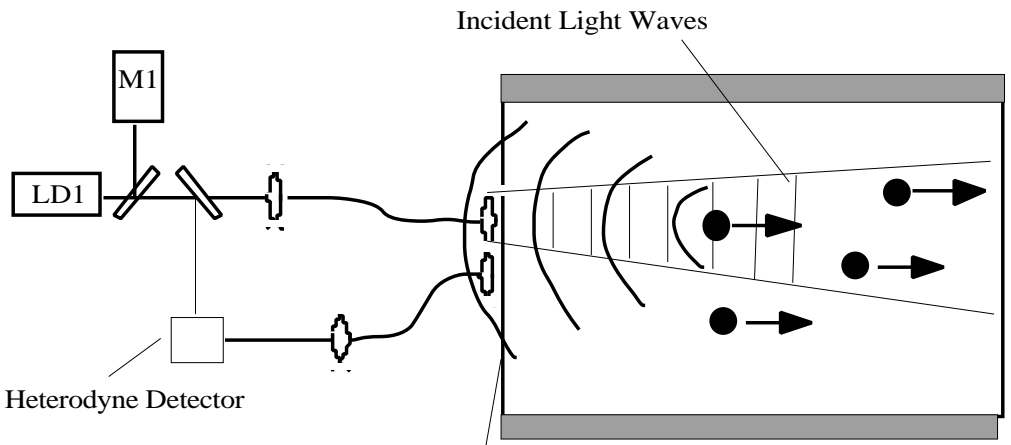

Back Scattered Light, red shifted longer wavelength.

Figure 2. Schematic layout of a Laser Doppler Velocimeter. The diagram shows the incident light waves being scattered from a moving water droplet. The backscattered light is frequency shifted. The heterodyne detection enables the beat frequency between source and scattered light to be measured and the velocity $\mathrm{V}$ determined.

To determine the velocity of flow one can use Laser Doppler velocimetry. As a result of the Doppler effect a monochromatic optical pulse of frequency $v$ scattered from an object moving with velocity $\mathrm{V}$ undergoes a frequency shift of $\Delta v=( \pm 2 \mathrm{~V} / \mathrm{c}) v$, where $\mathrm{c}$ is the speed of light. Depending on the objects relative velocity with respect to the detector one measures an increase (+) in frequency or (-) a decrease in frequency for motion away from the detector. The cosine of the component of velocity can be ignored for onaxis measurement, see figure 2 . The frequencyshift, measured by the heterodyne will then be a measure of the average velocity of the flow. Additional information about flow, turbulent or laminar, may be extracted from studies of the spread in frequency of the Doppler shifted signal. 


\section{$\underline{\text { Results and Discussions }}$}

Initial work has concentrated on identifying suitable wavelengths for determining the mass of water in a known sample volume. To achieve this required; $i$. identification of absorption features in the liquid and vapor phases, $i$. construction of a suitable test cell and iii. the use of a visible/near-IR spectrometer and a Fourier Transform InfraRed (FTIR) spectrometer.

Identification of Absorption Features.

Initial measurements were taken in the liquid phase at room temperature and ambient pressure in an HP UV/Vis spectrometer. Several spectra were recorded in the near infrared through cells of various optical path lengths. However, due to random variations in the cell quality, quantitative comparison was not possible but qualitatively the data confirms that the more absorber, i.e water, the lower the transmission through the sample.

In parallel with these initial measurements construction of a high-pressure high-temperature transmission (HPHT) cell was completed; essentially, a single phase (liquid filled) cell with a $\sim 75 \mathrm{~mm}$ optical path and a clear aperture of $25 \mathrm{~mm}$. This design proved sub-optimal for initial measurements due to the difficulty in achieving a reliable background measurement and the limited transmission at certain wavelengths due to the long optical path. To overcome these difficulties a new two-phase "T" shaped HPHT transmission cell was constructed with a 50 mm optical path and a $\sim 13 \mathrm{~mm}$ clear aperture. The optical ports were standard soda-glass plugs of low optical quality but sufficient for initial measurements and rated for high pressure. The optical measurements are made through the bridge of the $\mathrm{T}$ with the liquid reservoir in the stem. The system is capable of measuring the transmission of vapor or liquid under identical conditions depending on the angle of the cell: Stem down, transmission through vapor (liquid flows into the stem), stem up, transmission through liquid (the liquid flows into the optical chamber). Pressure is determined from the temperature measured by a thermocouple in the stem. The system is designed to operated up to a pressure of $8.5 \mathrm{M} \mathrm{Pa}(\sim 1000 \mathrm{psi})$ at $\sim 300 \mathrm{C}$.

Since it is expected that infield measurements will be predominately in the vapor phase, initial measurements were made in the "stem down", vapor position. To explore the near IR absorption spectrum of water more fully it is necessary to use the FTIR spectrometer. The HP UV/Vis spectrometer has a long-wavelength detector cut-off at $1.1 \mu \mathrm{m}$ which has proven too limited in its optical coverage for this project. The FTIR Spectrometer was converted to operate over the visible/near infrared spectral range. The window of greatest interest is from $900 \mathrm{~nm}$ to $1800 \mathrm{~nm}$ (good fiber properties and available sources) and covers three major absorption feature in liquid and vapor phase. Figure 3 is a plot of the transmission of $10 \mathrm{~mm}$ of liquid water at $25 \mathrm{C}$ and at 1 atmosphere pressure superimposed over the transmission through $50 \mathrm{~mm}$ of water vapor at 1.5 $\mathrm{M} \mathrm{Pa}(200 \mathrm{C})$. From this graph a $10 \mathrm{~mm}$ sample of liquid becomes completely opaque at longer wavelengths but has transmission windows at shorter wavelengths. If liquid is present in the sample then it will still be possible to find transparent windows to measure the amount of water 
in the liquid phase and the vapor phase. Note that the vapor lines are much sharper than the liquid absorptions and in the $900 \mathrm{~nm}$ to $1.0 \mu \mathrm{m}$ range the separation in absorptions will allow for identification of liquid and vapor.

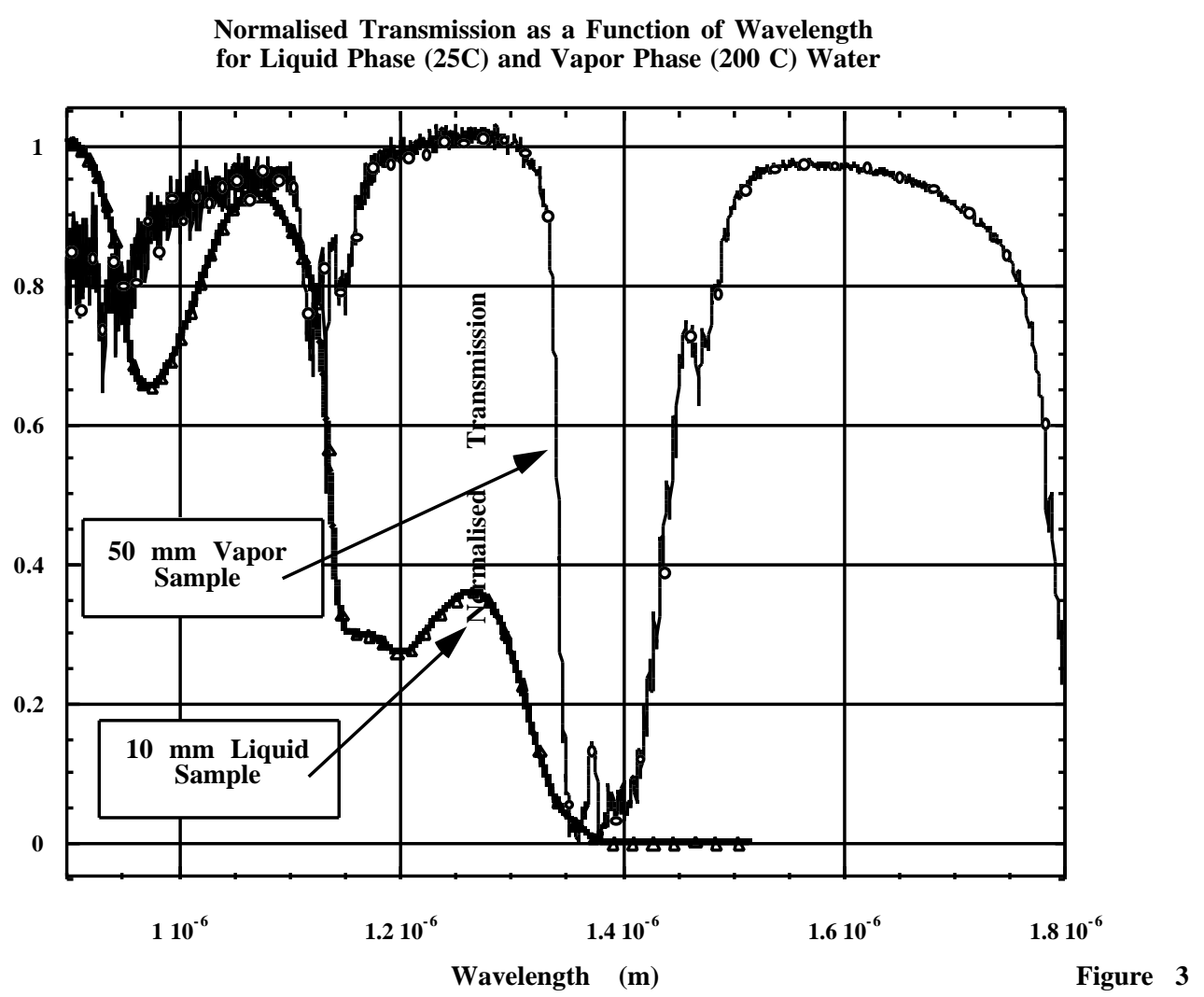

igure 3. This is a plot of transmission of near infrared light through a $10 \mathrm{~mm}$ sample of liquid water and a $50 \mathrm{~mm}$ sample of water vapor at $\sim 1$ atmosphers and $25 \mathrm{C}$.

To study the effect of increasing pressure on transmission. A series of transmission experiment was performed over a pressure range of $1.5 \mathrm{MPa}$ to $8.5 \mathrm{MPa}$ which corresponds to temperatures from 200 to $300 \mathrm{C}$; (pressures and temperatures expected infield). Measurements were made over the near-IR ( $900 \mathrm{~nm}$ to $1.8 \mu \mathrm{m}$ ) but only the data for the $900 \mathrm{~nm}$ to $1.2 \mu \mathrm{m}$ is plotted for greater clarity. These results are recorded in Figure 4 and are normalised at $1.66 \mu \mathrm{m}$ to correct for background errors. The general decline in transmission to shorter wavelengths is thought to be a combination of instrument, cell and background error exacerbated by corrosion of the optical windows. Due to the highly corrosive nature of water at these operating temperatures and pressures the inside of the optical windows became increasingly more frosted. This has the effect of increasing scatter at shorter wavelengths and thus increasing losses within the system 
rendering the initial experiments qualitative. Over a period of two hours the inside of the windows were completely frosted. Corrosion-resistant windows of higher optical quality (quartz or sapphire) will be used; a supplier is currently being researched.

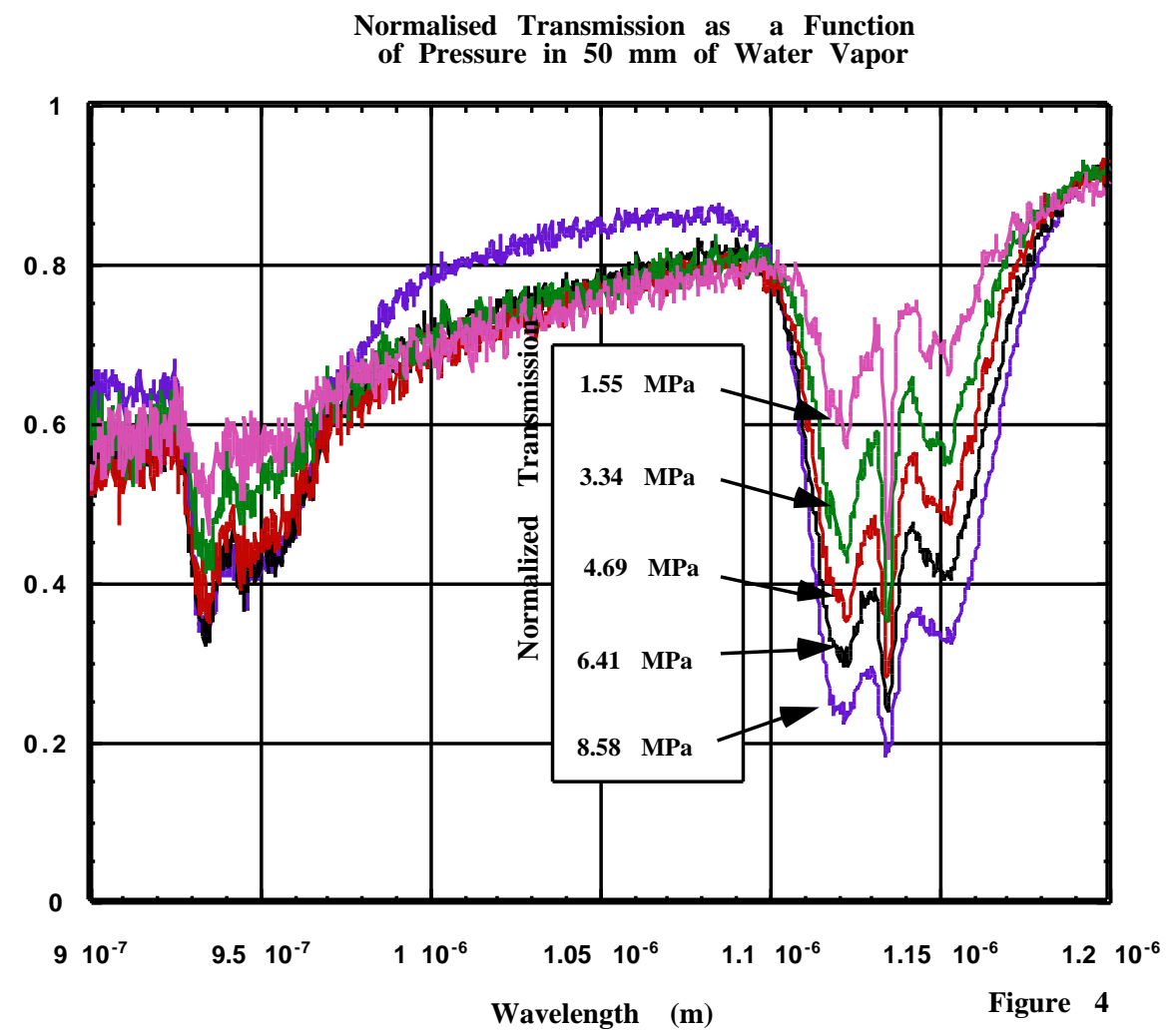

Figure 4. This is a plot of the transmission through a $50 \mathrm{~mm}$ sample of water vapor for several pressure.

The background spectrum for these runs, not shown, was taken through $50 \mathrm{~mm}$ of water vapor at $25 \mathrm{C}$. This background became more and more in error as the experiment progressed. This shows the necessity of having a self calibrating system measuring at more that one wavelength to remove background effects and to resolve liquid and vapor absorptions. There are two interesting features in Figure 4. The $938 \mathrm{~nm}$ water absorption line appears slightly shifted to higher frequencies (shorter wavelengths) and doesn't show in lower pressure runs. This may be an artifact of the technique used to obtain a background in this single beam instrument. The spectral absorption at $1.15 \mu \mathrm{m}$ gives excellent contrast over the desired pressure range. Figure 5 is a plot of the transmission, at three points on this $1.15 \mu \mathrm{m}$ feature. On the central spike and either side. 
Transmission v Presuure for 3 Optical Frequencies

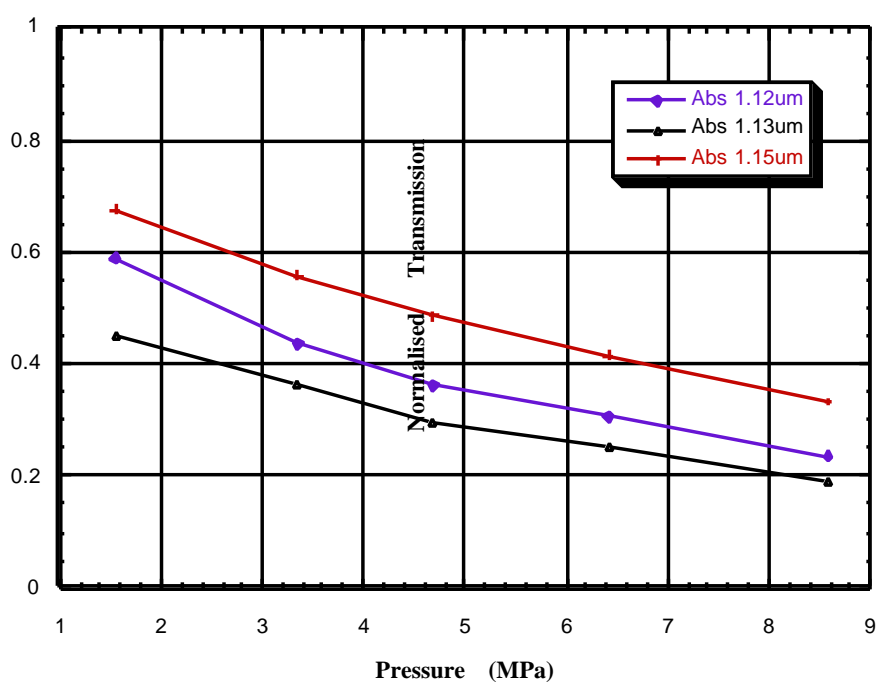

Figure 5

Figure 5. This is plot of the transmission of three different wavelengths as a function of increasing pressure, mass of water, within the test cell.

The results are plotted as transmission versus pressure. One can see as the pressure increases the transmission decreases at all wavelengths. This is a direct consequence of more absorbers (water molecules) being present in the sample as the pressure increases.

In addition to this work, a survey of commercially available Doppler velocimeters has been undertaken and a survey of suitable optical ports for inline flowing operations. Some of this work was reported at the Sixth Annual Historically Black Colleges and Universities and Other Minority Institutions Program, April 27-29, 1998 Ocean City, Maryland.

"Measurement of Downhole Steam Quality and Energy by Optical Methods".

\section{Future work}

In the next quarter work will continue on refining the HPHT transmission cells. Measuring the transmission of either liquid phase or vapor phase water under identical conditions using the " $T$ " cell with modified optical ports. In addition work will start on the construction of a flow loop apparatus with air-water mixtures for generating annular and mist flow simulation with known rates of each stream. The device will be tested in the flow loop to verify accuracy of measurement. The mating of commercial Doppler Velocimeters to this apparatus will be explored 


\section{Conclusions}

In the first sixth months of this project we are on track. A suitable spectrum has been identified over which the presence of liquid water and vapor can be identified. This is in the near infrared and extends from $\sim 900 \mathrm{~nm}$ to $1.8 \mu \mathrm{m}$ region. A high pressure and high temperature cell has been constructed and tested for stagnant transmissions. Minor teething problems have led to an improved design which will resist corrosion of the optical ports. These modifications will be incorporated in the next quarter.

The actual determination of the mass of water, either in liquid or vapor, has not been reliably determined, due in part to the teething problems addressed in the modifications. However, qualitative data has been recorded clearly showing an increase in absorption with increasing number of absorbing molecules i.e. mass of water present.

Over the next quarter construction of a two phase flowing cell will be undertaken and the velocity measurements apparatus will be further researched.

\section{References}

1. S.M. Farouq Ali, "Steam Injection Theory and Practice", Heavy Crude Oil Recovery, Ender Okandan, ed. Series E Applied Sciences No. 7, Publ. By Martinus Nijhoff, 1984, P 49-68.

2. Proceedings of the NATO Advanced Studies Institute on Heavy Oil Recovery, for meeting of June 21-July 4, 1982, Ender Okandan, ed., Publ. by Martinus Nijhoff, Preface.

3. V.A. Kuuskraa, et. at., "Major Tar Sands and Heavy Oil Deposits of the United States", from Exploration for Heavy Oil and Natural Bitumen, Richard F. Meyer, ed., AAPG Series in Geology \#25. Publ. by the American Association of Production Geologists 1984, p 123135.

4. G. Paul Willhite, "Over-all Heat Transfer Coefficient in Steam and Hot Water Injection Wells", JPT, May 1967, p 607-615

5. D.P. Aeschliman, "The Effect of Annulus Water on the Wellbore Heat Loss from a Steam Injection Well with Insulated Tubing", SPE Paper No. 13656, presented at the 55th California Regional Meeting, March 27-29, 1985.

6. G. Paul Willhite and Suzanne Griston, "Wellbore Refluxing in Steam Injection Wells," JPT, March 1987, p 353-362.

7. Sze-Foo Chien,"Determination of Steam Quality and Flowrate using Pressure Data from an Orifice Meter and a Critical Flowmeter", SPE Production and Facil., May 1995, p 7681

8. Clifford L. Redus, "Measurement of Steam Quality and Mass Flow Rate", Patent \# 5,421,209 June 6, 1995.

9. A. R. Shouman, "Steam Quality Measurement: A State-of-the-Art Review", Sandia National Laboratories Contractor Report, SAND80-7134, December 1981

10. Martin W. Woiceshyn, et. al., "Steam Quality Measurements by Neutron Transmission", Third International Conference on Crude and Tar Sands, Long Beach, CA, July 22-31, 1984. 